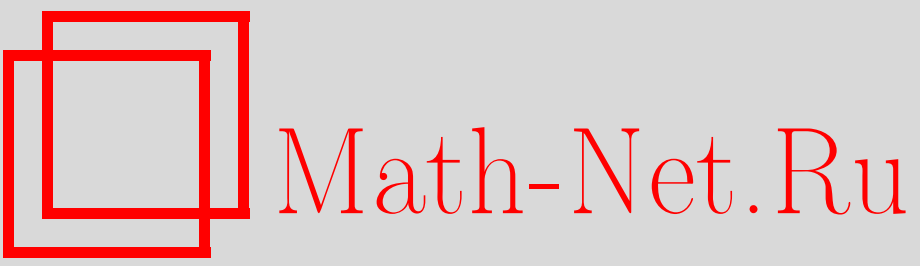

В. А. Ватутин, Об обществе Бернулли по математической статистике и теории вероятностей, Теория вероятн. и ее примен., 2010, том 55, выпуск 4, 820-822

DOI: https://doi.org/10.4213/tvp4287

Использование Общероссийского математического портала Math-Net.Ru подразумевает, что вы прочитали и согласны с пользовательским соглашением

http://www.mathnet.ru/rus/agreement

Параметры загрузки:

IP: 54.81 .137 .203

26 апреля 2023 г., 17:30:51 


\section{ОБ ОБЩЕСТВЕ БЕРНУЛЛИ
ПО МАТЕМАТИЧЕСКОЙ СТАТИСТИКЕ И ТЕОРИИ ВЕРОЯТНОСТЕЙ}

Одним из самых авторитетных обществ в мире, объединяющих специалистов по теории вероятностей и математической статистике, является Общество Бернулли. Это общество было организовано в 1975 г. в результате преобразования секции «Международная ассоциация по статистике в физических науках», существовавшей с 1963 г. в составе Международного Статистического Института (IMS). По предложению Джерси Неймана новое общество использовало в своем названии фамилию Бернулли, признав выдающийся вклад этого семейства в различные области физики и математики, включая пионерские работы по теории вероятностей и математической статистике.

В объявлении о создании Общества Бернулли, появившемся в 1976 г. в журнале «Stochastic Processes and Their Applications», было заявлено, что целью общества Бернулли является «...развитие, на основе международных соглашений и международного сотрудничества, теории вероятностей и математической статистики, а также расширение применения этих областей науки в таких разделах человеческой деятельности, которые углубляют познания о природе и ведут к повышению благосостояния человечества». В настоящее время членами Общества Бернулли являются примерно 1000 ученых из более чем 70 стран. Общество сотрудничает с рядом других, близких по духу ассоциаций ученых, таких как IMS.

Основными административными органами Общества являются:

1. Высший орган Общества - Генеральная ассамблея, образованная членами Общества;

2. Совет Общества, состоящий из президента, президента-электа и 12 членов. Шесть членов Совета обновляются каждые 2 года, а президента сменяет президентэлект, становясь действующим президентом. Срок службы обычного члена Совета равен четырем годам. Совет Общества избирается Генеральной ассамблеей в соответствии с рекомендациями Комитета по выдвижениям, состоящего из президента, президента-электа и трех членов, избираемых Генеральной ассамблеей;

3. Исполнительный комитет, состоящий из президента, предыдущего президента, президента-электа, научного секретаря, секретаря, ответственного за работу с членами общества, исполнительного секретаря и казначея.

Следующие ученые были президентами Общества Бернулли: D. Kendall (Великобритания), 1975; D. Blackwell (США), 1975-1977; K.Krickeberg (ФРГ), 1977-1979; D. Cox (Великобритания), 1979-1981; P. Revesz (Австрия), 1981-1983; B. Scott (США), 1983-1985; C. Неyde (Австралия), 1985-1987; W. R. van Zwet (Нидерланды), 1987-1989; А. Н. Ширяев (СССР), 1989-1991; Р. J. Bickel (США), 1991-1993; O. E. Barndorff-Nielsen (Дания), 1993-1995; J. L. Teugels (Бельгия), 1995-1997; L. Chen (Сингапур), 1997-1999; D. O. Siegmund (ФРГ), 1999-2001; Р. Hall (Австралия), 2001-2003; D. Dawson (Канада), 2003-2005; P. Jagers (Щвеция), 2005-2007; J. Jacod (Франция), 2009-2011.

В настоящее время в состав Исполнительного комитета Общества Бернулли входят:

- президент: Victor Pérez-Abreu (Мексика),

- предыдущий президент: Jean Jacod (Франция), 
- президент-элект: Edward Charles Waymire (США),

- научный секретарь: Nakahiro Yoshida (Япония),

- секретарь, ответственный за работу с членами общества: Josef Steinbach (Германия),

- исполнительный секретарь: Ada van Krempen (Нидерланды),

- казначей: José Manuel Corcuera (Испания).

Официальными журналами Общества Бернулли являются журналы «Bernoulli» и «Stochastic Processes and Their Applications». Кроме того, Общество Бернулли оказывает (наряду с другими организациями) финансовую поддержку следующим электронным изданиям: «Electronic Communications in Probability», «Electronic Journal of Probability», «Electronic Journal of Statistics», «Probability Surveys and Statistics Surveys».

Дважды в год Общество осуществляет выпуск бюллетеней «Bernoulli News», в которых подробно освещается деятельность Общества. Кроме того, раз в два месяца производится рассылка электронных писем «Bernoulli E-Briefs», в которых отражается текущая деятельность Общества и публикуется актуальная информация, представляющая интерес для ее членов.

Общество Бернулли организует и спонсирует ряд международных мероприятий, таких как Всемирные конгрессы по теории вероятностей и математической статистике (до 2004 г. - Всемирные конгрессы Общества Бернулли), проходящие раз в четыре года, ежегодные конференции по случайным процессам и их применениям, Всемирные статистические конгрессы (раз в два года), Латино-Американские конгрессы по теории вероятностей и математической статистике (раз в два или три года) и ежегодные конференции европейских статистиков.

В 2010 г. Общество Бернулли проводило или финансово поддерживало следующие мероприятия:

- 28-ю Европейскую конференцию по статистике (Пиреи, Греция, 17-22 августа);

- сателлитную конференцию (к Международному конгрессу математиков) по теории вероятностей и случайным процессам (Бангалор, Индия, 13-17 августа);

- 34-ю конференцию по теории вероятностей и математической статистике (Осака, Япония, 6-10 сентября);

- Всемирный день статистики 20-го октября 2010 г.

В 2011 г. при поддержке Общества Бернулли будут проходить следующие мероприятия:

- 35-я конференция по теории вероятностей и математической статистике (Оахака, Мексика, 19-25 июня); официальный сайт конференции: http://www.matem. unam.mx/SPA2011;

- сателитная конференция (к Всемирному статистическому конгрессу) по динамике статистических моделей (Копенгаген, Дания, 17-19 августа); информацию об этой конференции можно запросить по адресу: susanne@math.ku.edu;

- 58-й Всемирный статистический конгресс (Дублин, Ирландия, 21-26 августа); официальный сайт: http://www.isi2011.ie.

Кроме того, с 9 по 14 июля 2012 г. в Стамбуле (Турция) запланировано проведение 8-го Всемирного конгресса по теории вероятностей и математической статистике (http://www.worldcong2012.org).

Отметим, что Первый Всемирный конгресс Общества Бернулли состоялся в г. Ташкенте (СССР) в 1986 г. Местами проведения последующих конгрессов были города: Уппсала (Швеция), 1990; Чапел Хилл (США), 1994; Вена (Австрия), 1996; Гуанахуато (Мексика), 2000; Барселона (Испания), 2004; Сингапур (Сингапур), 2008.

Общество Бернулли (http://www.bernoulli-society.org) является открытой асcoциацией ученых, и каждый, кому близки его цели, может стать членом этого общества. Для этого достаточно заполнить соответствующую анкету на сайте http://isi.cbs.nl/bern-form.asp и уплатить вступительный взнос. 
Размер вступительного взноса (а также последующих ежегодных взносов) для ученых из России равен 35 евро.

Аспиранты и студенты освобождены от вступительных взносов. По вопросу вступления в Общество им необходимо предварительно обратиться к профессору Йозефу Штейнбаху (Josef G. Steinbach) по адресу: jost@math.uni-koeln.de.

Преимущества членства в Обществе Бернулли таковы:

- уменьшенный оргвзнос на мероприятиях, организуемых или спонсируемых Обществом;

- свободный доступ к электронным выпускам журналов «Bernoulli» (начиная с первого выпуска 1995 г.) и «Stochastic Processes and Their Applications» (начиная с первого выпуска 1973 г.);

- получение печатной версии выпусков бюллетеней «Bernoulli News», а также раз в два месяца электронных писем «Bernoulli E-Briefs» о мероприятиях, относящихся к области интересов его членов;

- специальные цены на подписку для ряда журналов по теории вероятностей и математической статистике.

Член Европейского регионального комитета Общества Бернулли B. A. Bатутин

\section{МЕЖДУНАРОДНАЯ КОНФЕРЕНЦИЯ «СОВРЕМЕННАЯ СТОХАСТИКА: ТЕОРИЯ И ПРИМЕНЕНИЯ ІІ»}

C 7 по 11 сентября 2010 г. в Киеве, Украина, прошла международная конференция «Современная стохастика: теория и применения II». Конференция была посвящена юбилеям выдающихся украинских математиков Анатолия Владимировича Скорохода, Владимира Семеновича Королюка и Игоря Николаевича Коваленко. Организаторы конференции - Киевский национальный университет имени Тараса Шевченко, Институт математики Национальной академии наук Украины, Национальный педагогический университет имени Михаила Драгоманова и Национальный технический университет Украины «Киевский политехнический институт».

В состав Программного комитета вошли: В.Королюк - председатель комитета, Ю. Козаченко - заместитель председателя, В. Анисимов, В.Булдыгин, А. Дороговцев, А. Дудин, А. Иванов, О. Клесов, П. Кнопов, И. Коваленко, Ю. Кондратьев, А. Кукуш, Е. Лебедев, Н. Леоненко, Н. Лимниос, Р. Майборода, Н. Працевитый, М. Савчук, Д. Сильвестров, А. Скороход, А.Фаль. В состав Организационного комитета вошли: О. Закусило - председатель комитета, А. Самойленко - сопредседатель комитета, Ю. Мишура - заместитель председателя, Н. Портенко заместитель председателя, А. Борисенко, Я. Елейко, Б. Копытко, А. Курченко, С. Махно, М. Моклячук, В. Радченко, Л. Сахно - ученый секретарь, Н. Семеновская, А. Станжицкий, Г. Торбин, Г. Шевченко, Т. Яковенко, Р. Ямненко, В. Ясинский.

Цель конференции - собрать лучших специалистов в теории вероятностей, теории случайных процессов, математической статистике и других разделах стохастической теории для совместного обсуждения современных научных проблем и привлечь к этому обсуждению молодых специалистов и аспирантов. Научная тематика конференции: диффузионные процессы, фрактальный анализ, гауссовские и смежные процессы и случайные поля, обобщенные процессы восстановления, информационная безопасность, системы частиц со взаимодействием, предельные теоремы для случайных процессов и полей, марковские и полумарковские процессы, математика финансов, системы обслуживания, процессы риска и актуарная математика, статистика случайных процессов, стохастический анализ, стохастические дифференциальные уравнения, стохастические модели эволюционных систем. В работе конференции 